\title{
Procesos de literacidad en jóvenes y adultos: convergencia de instituciones y sujetos
}

\author{
Maria del Carmen Lorenzatti*
}

\section{Resumen}

En este artículo se analizan prácticas de literacidad desplegadas por una señora de nula escolaridad. Desde la perspectiva de los nuevos estudios de literacidad se propone argumentar que estas prácticas forman parte de procesos sociales más amplios donde se entrelazan conocimientos de los sujetos sobre la cultura escrita, demandas que las instituciones realizan en relación con la lectura y escritura y relaciones de poder. Se trata de un estudio socioantropológico, de corte etnográfico. Interesa especialmente desentrañar las relaciones entre las distintas escalas de contextos locales y globales para mostrar que las prácticas de literacidad no pueden ser consideradas en forma abstracta, disociadas de sus condiciones históricas, políticas, económicas, sociales y culturales. Este estudio pretende aportar conocimientos para repensar la práctica docente en el campo de la educación de jóvenes y adultos.

Palabras claves: Literacidad. Práctica social. Adultos de nula escolaridad.

\footnotetext{
* Profesora del Centro de Investigaciones Maria Saleme de Burnichon, Facultad de Filosofia y Humanidades. Universidad Nacional de Córdoba. 


\section{Introducción}

La situación del acceso a la cultura escrita de jóvenes y adultos preocupa a los gobiernos de la Región desde hace muchos años. Se han realizado esfuerzos a nivel internacional y nacional para ofrecer una respuesta pero generalmente están centrados en las miradas cuantitativas de la problemática. Los maestros también están preocupados, buscan respuestas para abordar "la heterogeneidad de sujetos, edades, intereses, necesidades" que encuentran en los espacios áulicos. A su vez, los sujetos jóvenes y adultos con los que trabajo expresan que "conocen las letras pero no las pueden hacer hablar". Ellos acuden, abandonan y vuelven a participar en los distintos programas que se desarrollan desde esferas gubernamentales. En estos programas de alfabetización es común observar un trato infantilizado hacia los adultos. En el plano político se reproducen proyectos focalizados donde no se considera la posibilidad de inclusión o relación de los programas en otros programas de mayor alcance, que integren otros aspectos de la vida de las personas. En general se trata de acciones centradas en sujetos que aprenden de manera aislada.

En este artículo $^{1}$ se presentan resultados de una investigación doctoral ${ }^{2}$ que tuvo como objetivo general conocer las prácticas letradas que desarrollan adultos de nula/baja escolaridad en distintos espacios sociales (religioso, jurídico, doméstico, financiero, laboral y escolar) y las actividades y acciones que conforman estas prácticas a partir de propósitos y condiciones particulares.

En la investigación pude observar las prácticas desarrolladas por Margarita en torno a la literacidad y analicé su relación con los objetos escritos. Hablo de los recursos materiales y simbólicos presentes y los conocimientos que la señora tiene sobre los usos y las consecuencias legales de la literacidad. Es importante señalar que ella no asistió a la escuela cuando era niña. Según sus apreciaciones, su padre sostenía que eso era prohibido para las mujeres. Había una escuela muy lejos, donde iban sus hermanos varones. A los 16 años emigró a Argentina, trabajó como empleada doméstica y en el sector informal de la economía. Hoy tiene un hijo, dos nietos y vive sola.

En este texto presento a la señora Margarita, las características del espacio social doméstico donde vive y analizo cómo las prácticas de literacidad desplegadas en un trámite administrativo forman parte de procesos sociales más amplios donde se entrelazan relaciones de poder. Me interesa especialmente desentrañar las relaciones entre las distintas escalas de contextos locales y globales 
para argumentar que las prácticas de literacidad no pueden ser consideradas en forma abstracta, disociadas de sus condiciones históricas, políticas, económicas, sociales y culturales.

\section{Perspectiva teórico metodológica}

El acercamiento a la problemática se realizó desde la perspectiva de los Nuevos Estudios de Literacidad (KALMAN, 2003, 2004, 2008; STREET, 1984, 2005; ZAVALA, 2002), que considera a la literacidad como práctica social, donde cobra importancia el contexto de uso de la lengua escrita y las relaciones sociales y de poder que se generan. Se reconocen también los conocimientos que los sujetos adultos tienen de la misma, sus usos sociales y sus consecuencias.

Esta perspectiva surge a mediados de la década del ' 80 como respuesta a los postulados de la Gran División (WATT, GOODY, OLSON, ONG son los investigadores de esta línea). El estudio del campo de la cultura escrita toma un giro importante a partir del aporte de otros campos que contemplan la teoría de la alfabetización, entre ellos, el desarrollo de la psicología cultural y antropológica, la rama de la ciencia cognitiva y la investigación de la ciencia social interdisciplinaria sobre aprendizaje. Gillespie (2001) sostiene que un investigador que ayudó a definir este campo emergente, conocido como los Nuevos Estudios de Literacidad (New Literacy Studies, NLS) fue el antropólogo social Street (1984). El investigador inglés observando las prácticas de literacidad a través de un amplio rango de contextos alrededor del mundo, rechaza la noción de la alfabetización como la adquisición de destrezas y habilidades sin atender al contexto. El significado de la literacidad, afirma, depende de las instituciones sociales y culturales donde se desenvuelve. El acceso a la cultura escrita entonces no puede tratada como si fuese autónoma y separada de su significación política y cultural. De hecho, el autor afirma, es más apropiado referirse a las múltiples literacidades porque se enmarcan en diferentes prácticas sociales más abarcativas. Diversos autores (STREET, 1984; BARTON; HAMILTON, 1998; KALMAN, 1999, 2004; KALMAN; STREET, 2009) sostienen, a partir de estudios etnográficos, que son prácticas desarrolladas en contextos específicos. Por ello no se puede hablar de la lectura ni de la escritura sino "de lecturas y escrituras en plural para representar la multiplicidad de formas de leer y escribir en el mundo social" (KALMAN; HERNÁNDEZ, 2013, p. 4). 
Zavla, Niño Murcia y Ames (2004) sostienen que esta perspectiva teórica ofrece un marco desde donde desenmascarar la aparente neutralidad de las prácticas letradas y deconstruir sentidos comunes para proponer alternativas que respondan a la diversidad sociocultural de los países latinoamericanos. Al flexibilizar la relación entre oralidad y escritura la relación entre ambas se complejiza, se superpone la forma y función en la comunicación real en el marco de situaciones específicas. El concepto de literacidad destaca que la pluralidad de lo letrado es concebida como histórica y culturalmente construida y por ende, inserta en relaciones de poder.

Zavala (2002) reconoce distintas líneas dentro de los Nuevos Estudios de Literacidad (NEL). Menciona a las siguientes: Barton relaciona el concepto de literacidad con la lectura y escritura; Gee adopta un concepto más amplio y llega a cualquier sistema simbólico enraizado en la práctica social; Heath, la concibe como las variadas formas existentes de interactuar con el lenguaje alrededor de la escritura; Scollon y Scollon la vinculan con los patrones discursivos del lenguaje oral o escrito asociados a cualquier código desde donde se registran conceptos. Estas diferencias ayudan a complejizar el concepto y diferenciarlo explícitamente de la concepción de alfabetización, que estaría dando cuenta de una perspectiva técnico-metodológica desconectada de los procesos históricos y políticos que van marcando la vida de los sujetos. En esta línea, Zavala (2002) señala que el término alfabetización se asocia a un aspecto mecánico y se lo reduce al ámbito educativo, especialmente con la instrucción formal. Kalman (2004) habla de cultura escrita y reconoce que el vocablo alfabetización remite a atributos negativos, como es el analfabetismo o analfabeto, que imprimen un sello estigmatizante asociado a la posición social y al nivel educativo alcanzado.

En Brasil, desde los inicios de los NLS se habla de letramento como traducción de literacy. Tfouni et al. (2011, p. 162) considera que este concepto remite a "un proceso socio-histórico ocurrido en las sociedades que adoptan un sistema de escritura. Es un fenómeno de ámbito cultural extenso, se refiere a transformaciones sociales resultantes de los usos e influencia de la escritura en los hábitos y las concepciones de las personas"'.

En esta perspectiva no sólo hay que considerar las prácticas escritas sino también las practicas orales, se trata de una interpenetración de los discursos orales y escritos. Esta interpenetración, también llamada continuum, de las dos modalidades significa que la dicotomía lengua oral/lengua escrita ya no sirve y se 
pasa a considerar características de la lengua oral en la lengua escrita y viceversa. Lo que interesa es en qué medida el sujeto puede ocupar la posición de autor.

Marinho (2010, p. 17) sostiene que el concepto de letramento

[...] prevé referencias teórico-metodológicas capaces de dar cuenta de las competencias y habilidades discursivas, lingüísticas, técnicas, cognitivas, además de referenciar disposiciones y conocimientos que son condicionados por determinados factores históricos, sociales, políticos y culturales 4 .

En una publicación reciente (KALMAN; STREET, 2013) se presentan aspectos distintivos de los NLS desarrolladas por investigadores de América Latina y otros que trabajan en América Latina, en particular del Reino Unido y Estados Unidos. Los trabajos exploran la potencialidad de las prácticas de literacidad y numeracidad y su vinculación con trabajos de campos, específicamente matemática como práctica social y la multimodalidad como recurso socio-semiótico. Se analiza la naturaleza social de la lectura y escritura y su relación con realidades locales y globales y se estudian, desde distintos puntos de vista y posiciones teóricas, las relaciones institucionales y de poder en prácticas situadas. Se realizan desarrollos teóricos y análisis de experiencias en diferentes países de América Latina.

En mi investigación considero necesario establecer una articulación conceptual entre los Nuevos Estudios de Literacidad (NEL) y el enfoque histórico cultural, a partir del concepto de actividad de Leontiev (1994). Esta profundización teórica permite analizar aquellos procesos que, a través de las relaciones del ser humano con el mundo, satisfacen una necesidad especial y son desencadenados por motivos particulares de los sujetos. Hago referencia, de manera particular, al concepto actividad porque arroja luz al análisis del concepto de práctica social. En esta línea teórica se logra comprender cómo los usos situados forman parte de otras prácticas globales. Son los procesos de la actividad del sujeto que intervienen en sus relaciones con el mundo real; es la actividad la que media en la comunicación con las personas y que produce procesos de apropiación de los conocimientos acumulados en el género humano.

Las actividades que desarrollan los adultos estudiados, y en este caso, Margarita responden a diferentes motivos $y$, a su vez, se descomponen en acciones en función de sus propósitos y donde están presentes diversos recursos escritos. 
Desde la perspectiva de los NEL, las acciones se pueden considerar eventos letrados (HEATH, 1983) en tanto se desarrollan en situaciones donde circulan textos escritos que se enmarcan en instituciones o grupos sociales. También las acciones involucran formas de hablar, interactuar, pensar, valorar y creer.

Esta perspectiva se desarrolla y complejiza conjuntamente con el enfoque etnográfico y este trabajo es producto de un abordaje socio antropológico, de corte etnográfico porque permite observar la interacción social en situaciones in situ, registrar situaciones no documentadas y de esta manera ingresar al estudio de las situaciones particulares de la vida cotidiana (ROCKWELL, 2009).

Opté también por una estrategia metodológica de carácter intensivo porque representa la posibilidad de capturar las condiciones y procesos concretos que desarrollaron dos adultos en distintos espacios sociales. Achilli (2005) diferencia esta estrategia de la estrategia extensiva para superar la falsa dicotomía entre investigaciones de carácter cuantitativo y cualitativo. El carácter intensivo de esta investigación se complementa con una estrategia de acompańamiento que consiste en concurrir con una persona adulta (Margarita) a distintos lugares y observar sus prácticas de literacidad 5 . En cada uno de los acompañamientos observo las condiciones en que se producen y desarrollan estas prácticas. Considero no sólo las interacciones con los objetos escritos sino también las concepciones que la señora tiene sobre su condición lectora, entre otras cuestiones. Señalo además que en cada acompañamiento los diálogos mantenidos son orientados por los objetivos de la investigación. Es decir, no sólo se habla de cuestiones que responden a la visita coyuntural sino que en cada espacio, indago especialmente sobre la acción desplegada en relación con la investigación. Estas indagaciones se constituyen en entrevistas en profundidad aunque se manifiestan de distinta manera, en función de los contextos de participación.

Desde un enfoque contextual y relacional, el estudio arroja elementos para comprender que las prácticas de literacidad se constituyen a partir de situaciones singulares en el marco de prácticas más amplias y se encuentran atravesadas por las condiciones políticas, institucionales y sociales. En este marco analítico se puede entender cómo los sujetos que nunca fueron a la escuela o tuvieron que abandonarla por diferentes motivos son sujetos letrados.

\section{Ambientes letrados}

Para comprender por qué hablo de sujetos letrados considero necesario describir la casa donde vive Margarita porque es una vivienda con una fuerte 
presencia de objetos escritos. Está ubicada al fondo del patio, a unos pocos metros de la esquina. Tiene una tapia que la separa de la vereda y una puerta chica de chapa, que es un chapón con una manija que simula la puerta. Se ingresa a un pequeño comedor en cuya pared que da al frente de la puerta de ingreso hay un aparador de madera, (éste tiene una puerta abierta donde divisan muchas bolsas con remedios) y una heladera relativamente nueva. El techo tiene grandes pedazos de revoque caídos que dejan ver los ladrillos del cielorraso.

En la casa de Margarita hay una diversidad de recursos escritos. En las paredes del comedor se encuentran colgados de un clavo distintos "papeles" que son las boletas de los impuestos; también hay un almanaque y tres imágenes religiosas con oraciones escritas.

En la puerta de la heladera Margarita coloca imanes de diferentes formas y también se encuentran tarjetas de invitaciones a eventos barriales. El dormitorio es una habitación muy pequeña, angosta, con techo bajo. Tiene una cama en un rincón, un placard viejo de madera sobre una de las paredes; sobre la cama, un reloj de propaganda de Vía Valrosa (producto de belleza); al frente de la cama una ventana muy chica, con persianas de chapa y al lado de esta ventana, incrustado en la pared, se encuentra el teléfono con una casilla bloqueadora. Debajo de ésta se observa una mesa de plástico que sostiene un televisor blanco y negro muy pequeño, y detrás de éste está ubicado un radiograbador antiguo, con pasa casette. Detrás de la puerta del dormitorio está la alarma domiciliaria que la señora compró cuando trabajaba en una empresa de alarmas.

Señalo también que Margarita guarda, en una caja de zapatos, algunos materiales escritos referidos a cuestiones familiares. Se trata de fotos de la familia y distintas tarjetas que le envían sus familiares de Bolivia junto con una tarjeta que le regaló su nuera. Entre estos recuerdos ella me mostró una carta escrita por su hijo después de una pelea donde le expresa: "Has sido y sos para mí un gran ejemplo, a pesar de que has sido madre y padre a la vez, de cómo luchar y defenderse en la vida" (Ent.1, agosto de 2007). Margarita guarda la misiva y se siente orgullosa de su hijo. Este acto muestra el valor de documento que le otorga a la carta ya que esas palabras la definen como madre ejemplar.

En esta casa pude observar determinados objetos escritos referidos a diferentes cuestiones. Entre ellas menciono objetos relacionados a la salud (remedios y prospectos); a actos administrativos (boletas de impuestos); a situaciones jurídicas (contratos varios); a reuniones religiosas (Biblia de niños); a eventos familiares (fotos, tarjetas, cartas); a situaciones laborales (los catálogos 
de Avon). Todos ellos muestran que la literacidad es una actividad cotidiana para ella y que va más allá de adquirir una serie de habilidades y destrezas para interpretar los textos. Precisamente la presencia de los recursos mencionados dan cuenta que la literacidad está ubicada en el espacio entre el pensamiento y el texto (BARTON; HAMILTON, 1998).

\section{Margarita y el cobro del subsidio estatal: tramas contextuales que conforman las prácticas de literacidad}

La señora Margarita es una de las tantas personas que viven en una situación de pobreza en Argentina desde hace muchos años. Sus condiciones concretas de vida y la ausencia de un trabajo estable, la llevaron a salir a la calle para pelear por sus derechos. La necesidad de "sobrevivir la vida" la posiciona de una manera luchadora y la estimula para desarrollar diversas acciones que involucran procesos sociales donde está presente la literacidad. Una de esas acciones desplegadas por Margarita es cobrar un subsidio social.

A continuación presento un análisis que permite observar cómo diferentes situaciones de lectura y escritura se conectan a otras situaciones y a otros textos. Se estudia también de qué manera se entrecruzan instituciones que, a su vez, van incidiendo en las oportunidades de lectura y escritura que se le presentan a la señora estudiada.

Hago referencia a uno de los trámites que pude observar en un acompañamiento realizado con la señora Margarita: el cobro del subsidio estatal. Escojo este trámite porque los sectores gubernamentales y la prensa en general, presentan estos programas sociales como propuestas pensadas y organizadas para paliar la pobreza de los sujetos beneficiarios. Se difunden estos planes como si fueran proyectos que responden a las necesidades de los sujetos y que no ofrecen fisuras a la hora de recibirlos. Sin embargo, la experiencia vivida junto a Margarita muestra una cara distinta de este programa; precisamente cómo se generan falsas expectativas, cómo se prometen montos que luego no se pagan y por último, cómo se toman decisiones sin informar a los beneficiarios.

Desde el año 2002 y en el marco de políticas de inclusión social, el gobierno nacional comienza a implementar una serie de medidas a modo de paliativos para la situación de pobreza en la que se encontraba una amplia franja poblacional. El propio Estado reconoce su dificultad para operar sobre la estructura del mercado laboral y realiza un cambio conceptual de las políticas 
sociales; de los programas de subsidios transitorios (que adquirieron carácter de salario) a la condición de desempleo para lograr la reinserción laboral, se pasa a reconocer el derecho a un ingreso mínimo (no remunerativo) para las familias con jefe-a desocupado-a, manteniendo la obligatoriedad de la formación o contraprestación laboral ${ }^{6}$. En este marco nacional, el Estado provincial implementa un plan para personas solas, con las mismas características y administrado por distintas organizaciones barriales ${ }^{7}$.

En ese momento, Margarita se inscribe para recibir este beneficio pero luego le informan que no se lo iban a otorgar. Por esta razón ella moviliza a un grupo de mujeres del barrio para hacer el reclamo frente a una oficina estatal en el centro de la ciudad de Córdoba, que, según ella, tenía a su cargo la decisión sobre el otorgamiento de estos planes. Se contacta con algunos medios de comunicación y los cita a ese lugar. Una vez allí, ingresa al local junto a un grupo de compañeras para hablar con uno de los responsables. Esta demanda grupal favorece a Margarita porque finalmente cobra el beneficio.

\section{El inicio del trámite: objetos escritos e instituciones presentes}

El día que acompaño a Margarita a cobrar su mensualidad ilustra lo que significa recibir una "ayuda" del gobierno. Nos encontramos en la plaza principal del centro de la ciudad y caminamos hacia el Banco. La entrada de la entidad bancaria es un pasillo que lleva a un espacio grande, alargado, con 10 cajas de cobro. La señora muestra tener conocimiento de este lugar, sabe hacia dónde dirigirse. No hay gente esperando y entra directamente a una caja atendida por una mujer, haciendo caso omiso al tablero electrónico que indica con un timbre el número de cajero que corresponde. Entrega el Documento Nacional de Identidad, (documento que se entrega en todo trámite bancario), la cajera pregunta su apellido y luego su nombre y apellido para corroborar el dato que estaba leyendo en el documento.

A partir de la información de la computadora le informa a Margarita que el pago del mes no se encuentra registrado. Lo hace sin muchas explicaciones y le solicita que acuda a la institución que le otorgó el beneficio porque había ciertas indicaciones que se lo hubiesen quitado. Como respuesta a esta manifestación, Margarita expresa: "¿Por qué che?..¿Hoy pagan la mesa uno?.. A ver fijate bien... uhhhh...". 
La señora vive con esa mensualidad (cincuenta dólares) a la que suma lo ganado en su trabajo como empleada doméstica. Esta situación es una primera evidencia de cómo una disposición que se toma en un espacio institucional alejado del banco impacta en la vida de Margarita y la empuja a tomar decisiones inmediatas.

A partir de este caso, es posible articular cómo las prácticas de literacidad se componen de acciones que responden a propósitos particulares y que los recursos escritos se inscriben en las relaciones entre instituciones y personas en el marco de relaciones de poder. Hace falta poner la mirada en las condiciones políticas y sociales de las instituciones intervinientes en este trámite y cómo los documentos utilizados exigen que Margarita se relacione con las diversas personas involucradas.

Ir a cobrar el subsidio implica una serie de acciones donde la literacidad ocupa un lugar central. Margarita usa el documento nacional de identidad en forma correcta, se lo entrega a la cajera de la manera convencional para que lo pudiera leer. En este ejemplo se incorpora también la pantalla y la lectura de información que allí se le expide arroja datos que fueron decididos por otras personas y que no explicitan por qué razón se produce esta interrupción en el pago. Señalo esto de manera puntual porque comienza a derribarse la visión de la bondad organizativa de estos programas que se implementan para solucionar los problemas a las personas pobres.

A su vez quiero señalar que la señora realiza todos los pasos convencionales y organizados para poder cobrar el subsidio. Ella llega temprano, se dirige al lugar correspondiente, presenta la documentación correcta y sin embargo no puede cobrar. En este caso, las prácticas de literacidad están involucradas en un sistema de relaciones de poder porque son otras las personas que toman determinaciones sobre la vida de los receptores de estos subsidios, generando malestar e incertidumbre. Es la cajera quien lee la pantalla y le indica a Margarita que debe acudir a otro lugar, pero ella tampoco es quien ingresa los datos que traen estas consecuencias. La distancia física y social entre los que recogen la documentación con la información pertinente, los encargados de tomar las decisiones y la cajera que atiende en el banco es enorme. No hay recursos para resolver este problema. Ni la cajera ni la señora pueden rectificar lo sucedido en el momento de su encuentro. La situación descarga de responsabilidad a la cajera (sólo le toca leer la pantalla e informar) y la recarga sobre el usuario.

También es evidente que en esta cadena de desencuentros no incide la nula escolaridad de Margarita. Les hubiera sucedido también a otras personas 
ya que el cobro no depende de la lectura de una pantalla o una notificación (que nunca llegó) que puede hacer el beneficiario. Es decir, no le sucedió esto por ser "analfabeta". La ejecución del pago del subsidio está ligada a varios factores donde ingresa el texto escrito a partir de los documentos que debía presentar y específicamente a decisiones que se toman relacionadas con cuestiones estructurales de otro orden. Es el final de una cadena de actividades relacionadas entre sí.

Decidida a buscar una respuesta a esta situación de ausencia de pago, Margarita se dirige a la institución que le otorga el subsidio. Ella conoce la ubicación física del lugar pero no la dirección exacta. Tampoco puede precisar el nombre de la institución. Sabe que no es el lugar donde se deciden la suspensión del pago porque la responsable de enviar la información sobre su asistencia escolar en una planilla confeccionada con ese fin, es la directora de la escuela donde asiste por la noche. Margarita expresa sus dudas sobre la efectividad de esta acción: "Capaz que en la escuela no me hayan pasado".

¿Por qué duda Margarita sobre la entrega del certificado por parte de la directora? Desde principios del año lectivo la señora no asiste a la escuela por razones de salud. Ella concurre a un hospital público y el médico le extiende el certificado correspondiente, un objeto escrito en un papel con sello y membrete. Este documento oficial la exime de asistir diariamente a la escuela. La maestra y la directora asumen y aceptan la condición de enfermedad de la señora y justifican sus inasistencias. Por esta razón, entregan la información correspondiente al Ministerio de Educación, desde donde se remite al Ministerio de Trabajo.

En este trámite se observa la presencia de objetos escritos que se derivan de otras instituciones y que cumplen funciones complementarias al Documento Nacional de Identidad.

El pago del subsidio, en este caso analizado, demanda la intervención de varias instituciones oficiales: la escuela de jóvenes y adultos, el Ministerio de Educación, el Hospital Público, el Ministerio de Trabajo y la entidad bancaria.

\section{Recorridos institucionales en busca del subsidio}

Siguiendo con el mismo trámite, ya en el Ministerio de Trabajo, Margarita explicó, primero a un empleado y luego a otro, los motivos de su visita y que tipo de subsidio cobra. 
En los diálogos entablados se observa una insistencia de la señora sobre el destino de su subsidio. En el primer momento explicita que acude a la repartición pública porque no le pagan el subsidio y ubica el tipo de ayuda que recibe. Luego pregunta en seis oportunidades seguidas qué pasó con su pago, una de ellas interpela directamente al empleado y le pregunta: “¿vos sabés algo?”. El empleado sugiere que acuda al lugar donde le otorgan el subsidio dejando entrever que es esa institución la que no presenta la documentación a tiempo. Margarita defiende su situación de estudiante de la escuela nocturna y dice claramente: "Por eso estoy estudiando todas las noches. Si. Ellos me lo pasan de ahi".

Frente a búsquedas sin respuestas claras Margarita sugiere la posibilidad de que le hayan cambiado el lugar de pago. El empleado consulta a un compañero y la señora insiste en la posibilidad del cambio de entidad bancaria y reafirma el conocimiento del documento nacional de identidad cuando se lo piden para continuar indagando. Al cabo de un rato la pantalla de la computadora arroja una información que será la correcta: debe ir a cobrar a otro banco.

Este relato muestra la convergencia de diferentes instituciones en una acción puntual de Margarita que le exige entablar relaciones con la literacidad. No sólo el manejo y conocimiento de documentos sino también la familiaridad con las instituciones donde las decisiones se plasman en objetos escritos, a la vez que realiza conjeturas sobre los posibles errores cometidos. Se observa cómo estas prácticas de literacidad son configuradas por las reglas sociales que regulan el empleo y la distribución de textos, prescribiendo las maneras de acceder a ellos.

Quiero señalar, en primer lugar, algunos aspectos estructurales de las políticas sociales: las medidas asistencialistas del gobierno provincial ingresan en la vida de Margarita a través de un subsidio y para cobrar un plus de dinero debe asistir a una escuela de jóvenes y adultos donde la relación con la cultura escrita adquiere otras características. Se trata de un tiempo y espacio determinado con sus compañeros y una maestra en un contexto educativo formal.

En segundo lugar, en relación con aspectos institucionales, el subsidio le demanda a la señora realizar trámites en el Ministerio de Trabajo y en la misma escuela de jóvenes y adultos, ya que es la directora quien certifica las asistencias y las eleva al Ministerio de Educación, quien da la orden del pago del subsidio. En este caso debe tramitar certificado en el hospital.

En tercer lugar, quiero referirme a la escala correspondiente a la burocracia del sistema financiero que cambia el lugar del cobro y en este sentido, no se 
informan las razones por las cuales a partir de ese mes se paga en otro Banco, que es de jurisdicción nacional, diferente al que Margarita asistía en los últimos tiempos: ¿quién lo decidió? ¿Por qué no informaron correctamente? ¿Qué significa este cambio? No se había notificado debidamente ni a las personas involucradas ya que la cajera de la primera institución bancaria no lo sabía. Para ella, cobrar en el otro banco implica acudir a otro lugar, significa tiempo, traslado y gasto. Afortunadamente, conoce muy bien ese otro banco.

En este análisis se destaca, por un lado, los conocimientos de la señora sobre el valor social y las consecuencias legales del certificado de asistencias que la directora debe remitir. Por otro lado, la actitud vigilante de la señora frente a las respuestas de las instituciones mediadas por la burocracia de los trámites. Es ella quien desconfía de la entrega de los datos desde la escuela al Ministerio de Trabajo y quien le dice al empleado de esta institución que el problema posiblemente esté en el cambio de lugar de pago.

Mencioné anteriormente que la situación del no pago del subsidio excede la situación de nula escolaridad de Margarita y se relaciona con otras cuestiones ligadas a la burocracia del sistema financiero. En este sentido, vuelvo a señalar la importancia de su actitud, de su pelea por ejercer los derechos y el papel que juega en cada una de las acciones la creencia y los recursos simbólicos de la señora sobre el valor de la literacidad.

Este trámite, en términos de objetos escritos, despliega y pone en juego una serie de formularios que Margarita debe firmar, la maestra completar, los empleados del Ministerio de Educación elevar a otra oficina donde se cargan en computadoras. Los datos de la señora, su Documento Nacional de Identidad, la asistencia, su domicilio, su condición social recorren esos carriles que desembocan luego en un beneficio económico mensual de 50 dólares. Esta es la construcción histórica de los "papeles" que circulan en este mundo de los adultos estudiados.

Se hace necesario señalar también que durante esta actividad Margarita desarrolla diferentes acciones, se relaciona con distintas personas, explica los propósitos en cada intervención, reconoce e interactúa con diferentes recursos escritos. Para llegar al Banco de la Provincia de Córdoba la señora viaja en transporte público. Debido a que no le pagaron el Subsidio en ese Banco Margarita se dirige al Ministerio de Trabajo en taxi y le indica hacia dónde dirigirse, específicamente le señala qué camino tomar para llegar a la otra institución. Allí le informan que el pago se hace en otro banco, el Banco de la Nación Argentina, recorrido que realizó caminando. 


\section{Literacidad y poder}

El estudio de los procesos de literacidad abre el horizonte analítico a los conocimientos que las personas tienen sobre la cultura escrita y a los procesos sociales que se establecen en las entidades públicas. Estas instituciones se constituyen en espacios donde Margarita escribe su nombre y a su vez, presenta los más variados documentos para la realización de trámites. Es decir que las exigencias institucionales para cualquier trámite giran no sólo en torno a la firma para certificar algún dato sino también en la presentación de papeles en distintos momentos del trámite administrativo. Sin estos documentos no es posible pensar en acciones diversas.

La escritura del nombre y apellido remite a la identidad y, desde el punto de vista de las instituciones, se interpela a los sujetos como ciudadanos ya que deben dejar la impronta de su firma para dar cuenta de un trámite administrativo (en este caso, el cobro del subsidio estatal). Desde este lugar, la firma del nombre es una imposición institucional y forma parte de lo que se conoce como literacidad impuesta (IVANIC; MOSS, 2004). Sin embargo si por distintos motivos los sujetos no firman las instituciones tienen otras formas de dejar asentado el consentimiento del trámite. Por ejemplo, se le pinta el dedo o bien dibujan una cruz en el lugar correspondiente a la firma. Por lo tanto la firma de su nombre y apellido no es una cuestión excluyente a la hora de realizar un trámite. Margarita demuestra conocimiento del código escrito en ese contexto particular del trámite.

Esta práctica de literacidad situada responde a las demandas institucionales y la señora conoce de qué manera participar. Saber qué y saber cómo no son categorías universales, se tratan de conocimientos que se van apropiando en la vida cotidiana. (HELLER, 1997) Los sujetos de esta manera van respondiendo a las situaciones sociales que se le presentan y van configurando los contextos a partir de sus experiencias anteriores (KALMAN, 2003).

Estas maneras de actuar van demostrando también los valores que le otorga Margarita a los documentos para ser presentados en estas entidades. Las instituciones solicitan objetos escritos para certificar, acreditar y dar entidad material a las personas que acuden para solicitar algo. Margarita se apropió de ese saber porque siempre las instituciones demandan papeles que crean obligaciones y acuerdos. 
Estos "papelitos que hablan" (NIÑO MURCIA, 2004) desnudan mecanismos de control que las entidades públicas despliegan para controlar y registrar las acciones de los ciudadanos. De esta manera se van conformando archivos de datos personales con los usuarios y/o beneficiarios. Esto no es privativo de las entidades públicas, sucede también con otras instituciones privadas.

En este sentido, la literacidad no es neutral es absolutamente funcional a las instituciones y ayuda a generar relaciones de poder en espacios sociales específicos. Este es un ejemplo claro de conocimiento del poder y uso de la cultura escrita, independientemente de cómo firman los sujetos, si deletrean o si firman convencionalmente.

A la vez, una mirada a las acciones desarrolladas por la señora Margarita en estos espacios permite analizar que conoce el valor de estos "papelitos" y por eso los archiva en su vivienda, porque conoce que estos documentos exigidos se constituyen en la llave de entrada para hacer cualquier reclamo. Por ejemplo, mantener en la mano el documento de identidad mientras viaja en el taxi para hacer el reclamo del subsidio estatal implica que la seńora sabe que sin ese papelito no puede iniciar ninguna demanda. O en el caso del pago de los impuestos, guarda las boletas pagas como manera de defenderse frente a algún cobro extra que suele suceder en las instituciones.

Estos relatos muestran que "el papelito habla" para las instituciones y también para los sujetos con diferentes funciones. Para las primeras, para controlar a sus clientes y decidir qué decisiones tomar en relación con los reclamos. Las bases de datos que se organizan en las instituciones aportan elementos e información para actuar. Para las personas, los documentos lo van constituyendo como ciudadanos participantes más allá de la firma de su nombre. Es la historia de las relaciones sociales establecidas lo que le van otorgando identidad a la literacidad.

Es necesario señalar que en la era de las comunicaciones no sólo habla el papelito sino también la pantalla de la computadora. Kalman (2008, p. 108) recupera el concepto de new literacies y sostiene que "Esta forma de conceptualizar el auge del uso de las TIC aborda la tecnología desde la perspectiva de su inserción en configuraciones sociales, en relaciones de poder asimétricas y el potencial que ofrecen como espacio para la representación y expresión de significados". 
Desde esta perspectiva me interesa analizar también la posición de Margarita en el reclamo realizado en el Ministerio de Trabajo.

La pregunta “¿Qué sale?” que manifiesta en el Ministerio de Trabajo cuando va a reclamar por el cobro del subsidio mientras el empleado busca sus datos en la computadora es una clara evidencia que la seńora conoce el valor de la pantalla y de los datos que en ella se registran. Allí también está archivada la información que ella necesita, la que da cuenta de su historia como ciudadana con todos sus datos. En esa pantalla se habla de ella y de su situación personal particular sobre el subsidio. Es una muestra de la asimetría entre el empleado, que tiene el conocimiento de lo que le sucede a Margarita y la señora que espera una respuesta favorable a su solicitud. Estas relaciones de poder forman parte de procesos de literacidad.

\section{Actividad, acciones y usos de la literacidad}

A lo largo del artículo he presentado las acciones realizadas por Margarita para concretar el cobro del subsidio estatal. Esto implica observar los recorridos institucionales realizados, los propósitos comunicativos en cada acción desplegada y los recursos de cultura escrita involucrados. Además, observo de qué manera estas acciones están enmarcadas en prácticas más amplias, atravesadas por distintas condiciones institucionales y relaciones sociales.

Una cuestión importante a señalar, siguiendo la teoría de la actividad humana, es que siempre se está frente a actividades específicas, cada una de las cuales responde a determinada necesidad del sujeto, tiende hacia el objeto que satisface dicha necesidad, desaparece al ser satisfecha y se reproduce nuevamente, ante condiciones completamente distintas (o no). Sin embargo, lo que es más importante para distinguir la actividad es el objeto de la actividad, porque es lo que le confiere determinada dirección (LEONTIEV, 1994).

Este abordaje conceptual permite distinguir la actividad y la acción como realidades no coincidentes entre sí porque una misma acción puede formar parte de distintas actividades, puede pasar de una actividad a otra, revelando con ello su propia independencia relativa. También puede ser que un mismo motivo se concrete en distintos objetivos y genere distintas acciones.

Una actividad que ocupa un lugar principal en la vida de Margarita es la pelea por ejercer los derechos que le corresponden. Está ligada a la necesidad básica de subsistencia, que es no sólo el objeto de su actividad sino también su 
motivo real. Esta actividad se compone de distintas acciones que responden a determinadas condiciones y en este caso se desarrollan, como lo describí en el punto anterior, en distintos espacios. Incluyo en esta actividad las acciones que responden a su necesidad de reclamar por el cobro un subsidio estatal y cómo cada una de estas acciones le demanda hacer diferentes usos de la literacidad.

Me interesa distinguir, por un lado, los usos de la literacidad que le exige el espacio social en las acciones desplegadas y por otro lado, los usos que Margarita hace de la literacidad en cada uno de ellos.

De acuerdo a lo observado, ejercer los derechos para Margarita implica recorrer instituciones y en cada una de ellas recibe como una demanda común el uso legal y burocrático de la literacidad. Tanto los cajeros de los diferentes bancos como los empleados del Ministerio de Trabajo exigen documentos que den cuenta de la identidad legal de los sujetos En el caso de la señora además le solicitan los documentos escritos que certifican acciones realizadas, tales como el certificado de enfermedad que solicita la maestra para demostrar que no puede asistir a la escuela. En todos estos casos, los objetos escritos tienen fuerza legal.

La señora Margarita, en general, responde a las solicitudes con los documentos que ella guarda porque se ha apropiado del significado de los archivos escritos como comprobantes, como registros de su historia administrativa. Conoce además que estos documentos son parte del control administrativo que el estado ejerce con las personas.

Sin embargo, me interesa mostrar en este escrito que la señora también ejerce otros usos de la literacidad en función de sus propósitos y motivos, en relación con la actividad. Por ejemplo, en relación con el cobro del subsidio estatal ejerce presión para lograr una respuesta por parte de los responsables de otorgar la información necesaria para percibir el dinero; usa su condición de alumna para mostrar que le corresponde cobrar ese dinero. Estos posicionamientos le permiten defenderse frente a las decisiones de otros y demuestra que cobrar ese dinero forma parte de un derecho que le otorga el estado por su condición de pobreza Es decir, frente a la imposición de un uso legal y burocrático Margarita resignifica los objetos escritos en función de sus propias necesidades.

En el espacio doméstico la señora hace un uso afectivo y administrativo de los documentos que guarda, se trata de fuentes históricas de su vida personal y familiar. Ella guarda documentos, fotos y tarjetas de sus hermanos, primos 
y nuera, objetos a los que agrega la historia de ese momento mientras los muestra. Entonces se constituyen en objetos con memoria, porque ella recrea los momentos vividos, relata qué sucedió en cada foto. Allí también guarda la documentación que le otorga identidad en un lugar seguro: la bolsa de nylon. Su argumento se basa en que es material impermeable que resguarda los "papeles" ya que éstos no se pueden mojar, ajar o romper. El hecho de guardar da cuenta de un proceso clasificatorio que la señora realiza sobre la documentación importante. En esa bolsa están los contratos de compra-venta de la casa; el contrato de la tarifa social; los impuestos de los distintos servicios de su casa. Son aquellos objetos escritos que la resguardan y le otorgan pertenencia: su casa, su luz, sus derechos humanos. Esto aporta elementos para visibilizar el lugar de la literacidad en esta actividad de ejercer los derechos que despliega la señora.

Barton y Hamilton (1998) sostienen que los textos escritos pueden actuar como evidencia, manifestación, amenaza y ritual. En los ejemplos aquí presentados considero que los textos escritos pueden ser evidencias de situaciones de pobreza pero a la vez ser apropiados como instrumentos legales para defenderse y solicitar que se modifiquen algunas condiciones de existencia. También se constituyen en evidencias de las historias personales y de los sentimientos filiales.

\section{Algunas reflexiones}

La intención del presente artículo es ofrecer herramientas que ayuden a desmitificar el valor absoluto de la escritura en la vida de las personas. Es necesario poner en debate la dimensión social de la literacidad y enfatizar que no se trata de habilidades y destrezas particulares y singulares porque esta mirada genera y profundiza la discriminación, la desvalorización y degradación de aquellos sujetos que no accedieron a la alfabetización convencional o a la escolarización.

En un caso concreto he analizado cómo se fueron configurando las prácticas de literacidad en el marco de otras prácticas que respondieron a motivos personales, particulares de la señora Margarita. He mostrado evidencias acerca de las prácticas de literacidad como prácticas sociales en el marco de procesos sociales más amplios y entrelazados con relaciones de poder.

He seńalado también que Margarita muestra tener conocimiento de una serie de "papeles", documentos, formularios, tarjetas, cartas, almanaques, 
documentos religiosos, cancioneros, boletas de impuestos que conforman su "pequeño mundo" (HELLER, 1997). A su vez, su vida cotidiana incluye acciones en instituciones que demandan otras prácticas, que exigen otros conocimientos donde siempre está involucrada la literacidad.

Se analizaron puntualmente las acciones y propósitos de la señora en el marco de una actividad para mostrar la compleja trama de relaciones sociales que ella entabla en la lucha por su derecho, en este caso particular, el cobro del subsidio estatal, y cómo la literacidad es parte de cada una de estas acciones. La convergencia de instituciones en el desarrollo de un trámite específico muestra cómo las mismas demandan prácticas de literacidad y a la vez generan procesos de apropiación de la literacidad. Ella conoce muy bien cómo participar y cómo responder a dichas demandas. Ella valora los documentos que debe entregar para acreditar su identidad personal y social.

Margarita demuestra haberse apropiado de ese conocimiento: siempre las instituciones demandan papeles que crean obligaciones y acuerdos. Recibir el subsidio estatal implica ir a la escuela de adultos para la señora y también solicitar un certificado de salud. Estos requisitos imponen prácticas de literacidad más allá de la mera firma de documentos, que fue el único momento de escritura que presencié fuera de la escuela.

Las políticas asistencialistas, la burocracia del sistema administrativo ingresan a la vida de la señora y le exige relacionarse con objetos escritos, no sólo a partir de los papeles mencionados sino también a través de la pantalla de la computadora que exhibe información válida para su vida.

Como consecuencia de estas acciones se puede decir que la señora participa de eventos letrados lo que significa enfrentar exigencias sociales e institucionales de cultura escrita. La participación en instituciones y en redes sociales les ofrece oportunidades de interactuar con textos de diferentes formatos, relacionarse con distintas personas, exponer sus puntos de vista, sus opiniones y escuchar las ajenas.

Decía Freire (1971) que el hombre está en la realidad, dialoga con ella y de esta manera va humanizándola, va temporalizando los espacios geográficos. Considero que este estudio aporta elementos para entender de qué manera se produce esta relación sujeto-realidad, cómo se van constituyendo a través de la participación en las distintas instituciones, como sujetos sociales, con capacidad de decidir sobre los caminos a seguir. 
Esta situación indica claramente el origen social de la literacidad porque en cada uno de ellos se habla, se lee y se escribe acerca de alguna cuestión, circulan objetos escritos, se los manipulan, se los conocen, y se guardan.

Quiero señalar la importancia de desarrollar estudios socios antropológicos porque permiten desentrańar, desagregar y analizar los procesos que se desarrollan, en este caso, en relación con la literacidad. Los conocimientos generados en esta investigación muestran que los sujetos adultos conocen, leen y escriben, tienen proyectos, sienten, piensan y en este marco la literacidad se constituye en un hecho de convivencia humana (KALMAN, 2005)

\section{Notas}

${ }^{1}$ El presente artículo ampliado y modificado fue presentado en el VII Congreso Internacional Cátedra UNESCO: lectura y escritura para el mejoramiento y la equidad de la educación en América Latina”, organizado por el Área de Lingüística Aplicada del Centro de Investigaciones de la Facultad de Lenguas, Universidad Nacional de Córdoba, Argentina durante los días 6, 7 y 8 de noviembre de 2013 en Córdoba.

2 "Conocimientos, prácticas sociales y usos escolares de cultura escrita de adultos de baja escolaridad", Tesis Doctoral, dirigida por la Dra. Judith Kalman (DIE/México) y codirigida por la Dra. Elisa Cragnolino (UNC/ Argentina).

${ }^{3}$ Traducción de la autora del artículo. La cita textual en portugués es la siguiente: "um processo socio-histórico ocorrido nas sociedades que adoptam um sistema de escrita. E um fenómeno de âmbito cultural extenso, refere-se a transformaçōes sociais resultantes dos usos e influencia da escrita nos hábitos e nas concepçôes das pessoas".

${ }^{4}$ Traducción de la autora del artículo. La cita textual en portugués es la siguiente: "esse conceito prevé referenciáis teorico-metodologicos capazes de dar conta das competencias e habilidades discursivas, linguísticas, técnicas, cognitivas, além de referenciar disposições e conhecimentos que são condicionados por determinados fatores históricos, sociais, políticos e culturais".

${ }^{5}$ Los acompañamientos se realizan a los siguientes espacios sociales: 
casa de té, supermercado, la empresa de energía eléctrica de Córdoba, distintos bancos y al Ministerio de Trabajo, a un evento religioso y a un estudio jurídico.

${ }^{6}$ La obligatoriedad de la contraprestación o formación significó que los adultos que reciben este plan deben realizar algunas tareas o acciones. Estas puede ser actividades comunitarias y de capacitación; finalización del ciclo educativo formal (EGB-3, polimodal o primaria/secundaria) porque uno de los objetivos es "mejorar los niveles de alfabetización", acciones de formación profesional; incorporación a una empresa a través de un contrato de trabajo formal.

${ }^{7}$ Disponible en: <http://www.trabajo.gov.ar/jefes/beneficiarios/index. asp>. Acessado en: 20 gen. 2007.

\section{REFERENCIAS}

ACHILLI, Elena. Investigar en Antropología Social: los desafíos de transmitir un oficio. Rosario: Laborde, 2005.

BARTON, David; HAMILTON, Mary. Local literacies: reading and writting in one community. London: Routledge. 1998.

FREIRE, Paulo. La educación como práctica de la libertad. Buenos Aires: Siglo XXI, 1971.

GILLESPIE, Marilyn. Research in Writing: Implications for Adult Literacy Education. In: COMINGS, John; GARNER, Barbara; SMITH, Cristine. The annual review of adult learning and literacy. San Francisco: Jossey-Bass, 2001. v. 2. p. 63-110.

HELLER, Agnes. Sociología de la vida cotidiana. Barcelona: Península, 1997.

IVANIC, Roz; MOSS, Wendy. La incorporación de las prácticas de escritura de la comunidad en la educación. In: ZAVALA, Virginia; NIÑO MURCIA, Mercedes; AMES, Patricia. Escritura y Sociedad: nuevas perspectivas teóricas y etnográficas. Lima: Red para el Desarrollo de las Ciencias Sociales en el Perú, 2004. p. 211-246.

KALMAN, Judith. Escribir en la plaza. México: Fondo de Cultura Económica, 2003. 
KALMAN, Judith. Saber lo que es la letra: una experiencia de lectoescritura con mujeres de Mixquic. México: Siglo XXI, 2004.

El origen social de la palabra propia. México: Conaculta; Consejo

Nacional para la Lectura y las Artes, 2005.

Dimensiones conceptuales en el campo de la cultura escrita. Revista Iberoamericana de Educación, Madrid, n. 46, p. 107-134, ene./abr. 2008.

KALMAN, Judith; HERNÁNDEZ, Oscar. Jugar a la escuela con pantalla y teclado. Archivos Analíticos de Políticas Educativas, Arizona, v. 20, n. 73, sep. 2013.

KALMAN Judith; STREET, Brian. Lectura, escritura y matemáticas como practicas sociales: diálogos con América Latina. Mexico: Siglo veintiuno; Crefal, 2009.

KALMAN Judith; STREET, Brian. Literacy and numeracy in Latin America: local perspectives and Beyond. New York: Routledges, 2013.

LEONTIEV, Aleksei. Uma contribução a teoria do desenvolvimento da psique infantil. In: VIGOTSKY, Lev S.; LURIA, Alexander R.; LEONT’EV, Aleksei Nikolaevich. Linguagem, desenvolvimento e aprendizagem. São Paulo: Icone, 1994.

MARINHO, Marildes; CARVALHO, Gilcinei Teodoro (Org.). Cultura escrita e letramento. Belo Horizonte: Editora UFMG, 2010.

NIÑO MURCIA, Mercedes. "Papelito manda": la literacidad en una comunidad campesina de Huarochiri. In: ZAVALA, Virginia; NIÑO MURCIA, Mercedes; AMES, Patricia. Escritura y Sociedad. Nuevas perspectivas teóricas y etnográficas. Lima: Red para el Desarrollo de las Ciencias Sociales en el Perú, 2004. p. 347-365.

STREET, Brian. Literacy and theory practice. Cambridge: Cambridge University Press, 1984.

Recent applications of new literacy studies in educational contexts. Research in the Teaching of English, Illinois, v. 39, n. 4, p. 417-423, 2005.

TFOUNI, Leda Verdiani; ASSOLINI, Filomena Elaine, FERRIOLLI;

Beatriz. Autoria e discurso pedagógico: questóes sobre o fracaso escolar. In: LORENZATTI, Maria del Carmen (Org.). Procesos de literacidad y acceso a la educación básica de jóvenes y adultos. Córdoba: Narvaja Editor, 2011. 
ZAVALA, Virginia. (Des)encuentros con la escritura: escuela y comunidad en los Andes peruanos. Lima: Red para el Desarrollo de las Ciencias Sociales en el Perú, 2002.

ZAVALA, Virginia; NIÑO MURCIA, Mercedes; AMES, P. (Org.). Escritura y Sociedad: nuevas perspectivas teóricas y etnográficas. Lima: Red para el Desarrollo de las Ciencias Sociales en el Perú, 2004. 
Processos de letramento em jovens e adultos: convergências de instituições e sujeitos

\section{Resumo}

No presente artigo, analisam-se práticas de letramento realizadas por uma mulher sem escolaridade. A partir da perspectiva dos novos estudos de letramento, argumenta-se que essas práticas são parte de processos sociais mais amplos onde se entrelaçam conhecimentos dos sujeitos sobre a cultura escrita, demandas que as instituiçóes realizam em relação à leitura, escrita e às relaçóes de poder. Trata-se de um estudo socioantropológico, de corte etnográfico, que tem interesse, em especial, em desvelar as diversas dimensóes das relaçóes que existem entre os distintos contextos locais e globais, com o intuito de demonstrar que as práticas de letramento não podem ser consideradas de maneira abstrata, dissociadas de suas condições sociais, isto é, históricas, políticas, econômicas e culturais. Este estudo procura aportar conhecimentos para repensar a prática docente no campo da educação de jovens e adultos.

Palavras-chave: Letramento. Prática social. Adultos sem escolaridade.

\section{Maria del Carmen Lorenzatti}

E-mail:marial@ffyh.unc.edu.ar
Literacy processes in young people and adults: convergence of institutions and actors

\section{Abstract}

The aim of this article is the analysis of literacy practices in the process carried on by a woman with no schooling. The purpose is to discuss, from the perspective of the recent literacy studies, that these practices belong to wider social processes where individual knowledge about the written culture are interlaced with the requirements of the institutions in relation to reading, writing and power relations. It is a socio-anthropological study, with an ethnographic kind. The focus is set on the comprehension of the relationship of the different scales of local and global contexts in order to prove that the literacy practices cannot be considered in an abstract way dissociated from its historical, political, economic, social and cultural conditions. This study intends to provide knowledge to rethink the teaching practice with young people and adults.

Keywords: Literacy. Social practice. Unschooled adult.

Recebido em: 19/11/2013

Versão final recebida em: 13/1/2014

Aprovado em: 2/2/2014 